\title{
Fertility management in Kallmann syndrome: a step towards optimization
}

\section{Shikha Bathwal, Sunita Sharma*, Nupur Agarwal, Baidyanath Chakravarty}

Department of ART, Institute of Reproductive Medicine, Kolkata, West Bengal, India

Received: 22 March 2017

Accepted: 21 April 2017

\section{*Correspondence:}

Dr. Sunita Sharma,

E-mail: sunitapalchaudhuri@yahoo.com

Copyright: (C) the author(s), publisher and licensee Medip Academy. This is an open-access article distributed under the terms of the Creative Commons Attribution Non-Commercial License, which permits unrestricted non-commercial use, distribution, and reproduction in any medium, provided the original work is properly cited.

\begin{abstract}
Kallmann syndrome (KS) is a genetic disorder with an incidence of one per 50,000 women. It is associated with hypogonadotropic hypogonadism and anosmia/hyposmia. An important aspect of managing KS is to achieve successful pregnancy. We hereby present a case series of three patients with KS who successfully conceived with human menopausal gonadotropin (HMG) induction. One patient achieved pregnancy with ovulation induction, second with fresh embryo transfer and the third with frozen embryo transfer. Two of these three women delivered at term and both babies were doing well at one year of follow up. Both received cyclical hormone therapy (HT) since adolescence. The third patient received HT only for six months before starting ovulation induction. She conceived twice but miscarried at both occasions. At times, it may be challenging to attain fertility in Kallmann syndrome but with persistent efforts results are usually rewarding. It is important to diagnose KS and start hormone therapy at appropriate time so that satisfactory fertility outcome can be achieved.
\end{abstract}

Keywords: Hormone therapy, Hypogonadotropic hypogonadism, Kallmann syndrome, Ovulation induction, Pregnancy

\section{INTRODUCTION}

Kallmann syndrome (KS) is a genetically heterogeneous disorder, occurring in one per 50,000 women, characterized by hypogonadotropic hypogonadism with hyposmia or anosmia.

Hypogonadism is due to GnRH deficiency which results from failure of embryonic migration of $\mathrm{GnRH}$ producing neurons because of gene mutation. ${ }^{1}$

These patients usually present with primary amenorrhoea and delayed puberty. In KS, successfully achieving a pregnancy poses a challenge to the clinicians. We report an interesting case series of three cases of infertility with female partner having $\mathrm{KS}$.

\section{CASE REPORT}

Case 1

A 34 year old married female came for infertility evaluation. She was diagnosed with KS at our clinic at the age of 17; since then she was started on cyclical hormone therapy (HT) and counseled about need of future fertility treatment. Karyotype was 46XX and KALL-1 gene was identified. During infertility evaluation, her BMI was $27.4 \mathrm{~kg} / \mathrm{m}^{2}$, her hormonal profile was abnormal (LH 1.05IU/l, FSH 1.77IU/l, E2 $12 \mathrm{pg} / \mathrm{ml}$ ) and AMH was $2.3 \mathrm{ng} / \mathrm{ml}$. On ultrasonography, uterine size was $6 \times 3.4 \times 2 \mathrm{~cm}$ with bilateral small ovaries (Volume $-1.9 \mathrm{cc}$ and $2.1 \mathrm{cc}$ ). Tubal patency and husband's semen analysis was normal. Ovarian stimulation was undertaken with gonadotropins using 150IU HMG for 8 
days starting from cycle day 2. It was increased to 225 IU in view of poor follicular growth. Later, as the patient developed five follicles $>14 \mathrm{~mm}$ and six follicles of size $10-14 \mathrm{~mm}$, they were counseled regarding switchover to IVF. After 22 days of stimulation and a total HMG dose of $4575 \mathrm{IU}$, hCG $10000 \mathrm{IU}$ was given for final oocyte maturation. Endometrial thickness (ET) was $13 \mathrm{~mm}$ and serum estradiol (E2) was $2660 \mathrm{pg} / \mathrm{ml}$ on the day of hCG. Eight oocytes were retrieved, five embryos were formed and two 8-celled embryos were transferred on day3. However, she did not conceive in that cycle. After 6 months, frozen embryo transfer (FET) was done. Two good quality embryos were transferred after endometrial preparation with estradiol valerate $(6 \mathrm{mg}$ daily) and vaginal progesterone $(600 \mathrm{mg}$ for 3 days prior to embryo transfer). Luteal support with estrogen-progesterone was continued till 12 weeks of gestation. A viable single intrauterine fetus was confirmed on ultrasound at 7 weeks and a healthy baby was born at term.

\section{Case 2}

A patient of $\mathrm{KS}$, diagnosed at the age of 20, presented to our clinic at 30 years with primary infertility. She was on HT for the past ten years. Her FSH, LH and E2 were very low and ultrasound showed uterine size of 20x29x58mm and small ovaries (Vol-2.1cc and $2.4 \mathrm{cc}$ ). She underwent ovulation induction with HMG 225IU from day 2 to day 15 resulting in two follicles $\geq 14 \mathrm{~mm}$ and was advised timed intercourse after confirmation of ovulation. Luteal support of estrogen and progesterone was continued till 12 weeks after confirmation of pregnancy. She also delivered a healthy baby at term.

\section{Case 3}

A 31-year female with BMI $17.2 \mathrm{~kg} / \mathrm{m} 2$ came with infertility and anosmia. She had withdrawal bleeding only following estrogen progesterone combination. Pelvic examination was normal. Her basal FSH, LH and E2 were $0.91 \mathrm{IU} / 1,0.07 \mathrm{IU} / 1$ and $9.8 \mathrm{pg} / \mathrm{ml}$ respectively. USG revealed hypoplastic uterus $(20 \times 24 \times 48 \mathrm{~mm})$ and bilateral small ovaries (Vol $1.3 \mathrm{cc}$ and $1.5 \mathrm{cc}$ ). CT scan of brain, karyotype were normal and KALL-1 gene was present. She was also diagnosed with KS. Other causes of infertility were ruled out. She had poor ET $(5 \mathrm{~mm})$ even after $12 \mathrm{mg}$ of estrogen therapy till day 21. Couple was counseled regarding small sized uterus and poor endometrial response to estrogen. After six months of priming with estrogen-progesterone, ovarian stimulation was started. A dose of 150IU HMG for five days resulted only in 4 follicles of $<10 \mathrm{~mm}$. This was followed by 225IU HMG for 19 days leading to five follicles of $>14 \mathrm{~mm}$ and three follicles of $<14 \mathrm{~mm}$. Six oocytes were retrieved and ET was $7.1 \mathrm{~mm}$ on day of retrieval. Five embryos were formed and two cleavage-stage embryos were transferred. Her $\beta$ hCG after 14 days of embryo transfer was $52 \mathrm{IU}$ but eventually led to a miscarriage. Endometrial preparation of the patient was attempted three times with high dose estrogen for FET but endometrium never crossed $5 \mathrm{~mm}$ when observed till day 30. Since surrogacy was not acceptable to the couple, they were counseled for second ovum pick up considering previous optimum endometrial thickness after ovarian stimulation. She was given HT for one year followed by ovarian stimulation with 225IU daily dose of HMG for 17 days. Total 7 follicles of $>14 \mathrm{~mm}$ developed, 6 oocytes were retrieved and ET was $7.3 \mathrm{~mm}$ on the day of ovum pickup. Two good quality blastocysts were transferred. She again conceived but ended up in missed abortion

\section{DISCUSSION}

In patients with $\mathrm{KS}$, the key aim, after diagnosis, is to induce and maintain secondary sexual characteristics by hormone therapy. Once these patients attempt to conceive, they require induction with gonadotropin in high dosages and for prolonged duration. Various ovulation induction protocols have been attempted for infertile women with this syndrome, such as using pulsatile GnRH, combination of recombinant FSH and LH, or HMG. ${ }^{2}$

In KS patients, approximately 120 pregnancies have been reported in the literature since $1990 .^{3}$ Most commonly used protocol for ovulation induction in women with $\mathrm{KS}$ is HMG. ${ }^{4,5}$ In the above case series, all three patients with KS achieved pregnancy with HMG induction. One patient achieved pregnancy with ovulation induction, second with fresh embryo transfer and the third with frozen embryo transfer. Out of the three, two delivered at term and both children were doing well at one year of follow up. Both these successful outcome patients received cyclical hormone therapy since adolescence. Their ovaries responded satisfactorily to gonadotropins and the uterus was well responsive to estrogen therapy. These two patients were diagnosed with KS during their pubertal years and were on hormone therapy since then. The third patient was diagnosed with Kallmann syndrome at 31 years and HT was given only for six months for priming before starting ovulation induction. Since her uterine size was very small $(20 \times 24 \times 48 \mathrm{~mm})$, growth of endometrial thickness was monitored with incremental doses of estrogen. Endometrial thickness was only $5 \mathrm{~mm}$ in spite of high dose of estrogen and guarded prognosis was explained to the couple. During ovarian stimulation with high dose gonadotropins, her endometrial thickness increased to $7.1 \mathrm{~mm}$. She conceived after embryo transfer but unfortunately had a missed abortion. After managing these three cases, we extrapolated that it is important to treat these women with hormone therapy from puberty onwards, not only to attain secondary sexual characteristics but also for satisfactory fertility outcome. In another case series, the author reported that follicular response to gonadotropins was insufficient in patients not previously primed with hormone therapy in comparison to hormone primed patients. ${ }^{5}$ Ovulation induction and conception can be achieved sooner and with less cost if they are previously primed..$^{5}$ 
A case report of Kallmann syndrome suggested that testosterone supplementation before ovarian stimulation dramatically improved follicular response to gonadotrophins in patient who was previously resistant to gonadotropin stimulation. ${ }^{6}$ Similarly, Balasch et al reported that LH priming in hypogonadotrophic hypogonadism women before ovarian stimulation with FSH may reduce the dose required for preovulatory follicular development. ${ }^{7}$ Although it may be challenging to attain fertility in Kallmann syndrome but with persistent efforts results are not always disappointing.

\section{ACKNOWLEDGMENTS}

The authors would like to thank Dr. Saeeda Wasim for helping in editing the manuscript.

Funding: No funding sources Conflict of interest: None declared

Ethical approval: Not required

\section{REFERENCES}

1. Cariboni A, Maggi R. Kallmann's syndrome, a neuronal migration defect. Cell Mol Life Sci. 2006;63(21):2512-26.

2. Buck C, Balasubramanian R, Crowley WF. Isolated gonadotropin releasing hormone $(\mathrm{GnRH})$ deficiency. Gene Reviews 2007.

3. Yu HT, Lee CL, Huang HY, Soong YK. Successful pregnancy in a woman with Kallmann's syndrome using human menopausal gonadotropin followed by low-dose human chorionic gonadotropin in the midto-late follicular phase. Taiwan J Obstet Gynecol. 2012;51(2):300-2.

4. Nakagawa K, Iwasaki W, Sato M, Ito M, Kawachiya S, Murashima A et al. Successful pregnancy, achieved by ovulation induction using a human menopausal gonadotropin low-dose step-up protocol in an infertile patient with Kallmann's syndrome. J Obstet Gynaecol Res. 2005;31(2):140-3.

5. Chryssikopoulos A, Gregoriou O, Papadias C, Loghis C. Gonadotropin ovulation induction and pregnancies in women with Kallmann's syndrome. Gynecol Endocrinol. 1998;12(2):103-8.

6. Sipe CS, Van Voorhis BJ. Testosterone patch improves ovarian follicular response to gonadotrophins in a patient with Kallmann's syndrome: a case report. Hum Reprod. 2007;22(5):1380-3

7. Balasch J, Fa'bregues F, Carmona F, Casamitjana R, Tena-Sempere M. Ovarian luteinizing hormone priming preceding follicle-stimulating hormone stimulation: clinical and endocrine effects in women with long-term hypogonadotropic hypogonadism. J Clin Endocrinol Metab. 2009;94:2367-73.

Cite this article as: Bathwal S, Sharma S, Agarwal N, Chakravarty B. Fertility management in Kallmann syndrome: a step towards optimization. Int J Reprod Contracept Obstet Gynecol 2017;6:2648-50. 